\section{Gêneros textuais em livros didáticos de história: enfoque na diversidade de textos verbais}

Textual genres in history textbooks: a focus on the diversity of verbal texts

Ana Gabriela de Souza SEAL (UFERSA) anagseal@ufersa.edu.br

\section{(1)}

SEAL, Ana Gabriela de Souza.

Gêneros textuais em livros didáticos

de história: enfoque na diversidade

de textos verbais. Entrepalavras,

Fortaleza, v. 7, p. 490-516, ago./dez.

2017.

Resumo: Buscamos investigar, no tocante ao ensino de História, quais gêneros textuais foram inseridos em duas coleções de livros didáticos, com o propósito de entendermos quais esferas sociais foram priorizadas. Orientamo-nos pela proposta de agrupamento dos gêneros textuais a partir de cinco ordens: narrar, relatar, descrever ações, expor e argumentar. Percebemos um esforço da coleção em atender ao Programa Nacional do Livro Didático e à Proposta Curricular Nacional, ambas de História, no que concerne à variedade textual e à multimodalidade de gêneros. No entanto, a quantidade dos demais gêneros frente aos textos didáticos, às legendas e àqueles referentes às propostas de atividades foram ínfimos. Consideramos indispensável discutir mais profundamente sobre a importância da diversidade textual nos livros de História e sobre os papéis que desempenham para o ensino de capacidades fundamentais à construção dos conhecimentos nessa área do saber.

Palavras-Chaves: Livros didáticos. Variedade textual. Linguagens. 
Abstract: We seek to investigate, as regards the teaching of history, which genres were inserted in two collections of textbooks, in order to understand which social spheres were prioritized. We are guided by the grouping proposal of genres in five orders: narrate, report, describe actions, expose and argue. We noticed an effort in the collection to meet the National Textbook Program and the Proposed National Curriculum, both of history, regarding the textual variety and multimodality of genre. However, the amount of other genres in comparison to didatic texts, subtitles and those related to the proposed activities were negligible. We consider indispensable to discuss more deeply the importance of textual diversity in history books and the roles they play for teaching basic skills to build knowledge in this area of knowledge.

Keywords: Textbooks. Textual variety. Languages.

\section{Introdução}

O discurso em favor do letramento ganha a cada dia mais notoriedade nas pesquisas educacionais. É em busca de contribuir para a ampliação dessa discussão que nos propomos, neste artigo, a discutir a variedade dos gêneros textuais nos livros didáticos de História da $1^{\mathrm{a}} \mathrm{a}$ $4^{\mathrm{a}}$ séries do ensino fundamental.

Inicialmente, é fundamental compreender que nos propomos a tecer investigações oriundas do campo da linguagem, articulandoas às necessidades originadas nas abordagens apresentadas no Ensino de História para os anos iniciais. Fizemos nosso recorte na análise da linguagem verbal presente em duas coleções de livros didáticos de História. Nossa compreensão é de que "Cada vez mais se observa a combinação de material visual com a escrita" (DIONÍSIO, 2011, p. 138), assim, os textos verbais apresentados nos materiais em análise são integrados aos visuais. Optamos por realizar o recorte de análise no texto verbal em busca de tecer considerações para esse elemento, sobretudo ao retratar a relevância deste para o ensino e a aprendizagem da linguagem nos anos iniciais do ensino fundamental.

Partimos da concepção de letramento enquanto "um conjunto de práticas de leitura e escrita que resultam de uma concepção de o quê, como, quando e por quêler e escrever" (SOARES, 2002, p. 75). Concebemos que a ampliação dos níveis de letramento ocorre durante toda a vida dos indivíduos, nas diferentes esferas de interação social. Na escola, as ações voltadas para tal finalidade são mais sistemáticas e planejadas. Ao adotarmos esse pressuposto básico, estamos compreendendo que a apropriação das atividades de leitura e escrita ocorre gradativamente à medida que os alunos se deparam com situações em que precisam lidar com o texto escrito. Ou seja, em situações que não são restritas às aulas 
v. $7(2)$

490-516 ago/dez 2017 de "Língua Portuguesa". É fundamental que as estratégias de leitura e produção de textos sejam desenvolvidas em situações em que os alunos tenham que refletir sobre temáticas oriundas de diferentes áreas de conhecimento. Para isso, é necessário que os discentes convivam com textos de diferentes gêneros que circulam na sociedade.

Buscamos investigar, no tocante ao ensino de História, quais gêneros textuais foram inseridos em duas coleções de livros didáticos, com o propósito de entendermos de quais esferas sociais de interlocução são selecionados nos materiais textuais a serem lidos/apropriados pelos estudantes. Para tal análise, consideramos necessário explicitarmos o conceito básico que será mobilizado no trabalho: gênero textual.

\section{Gênero textual: ensino da linguagem e multimodalidade}

O princípio básico da teoria dos gêneros textuais, em uma perspectiva bakhtiniana, é que as práticas sociais exercidas através do uso da linguagem são concretizadas nos gêneros textuais: cartas, bilhetes, propagandas, anúncios, e-mails, etc.

Desse modo, os gêneros textuais são compreendidos aqui enquanto "tipos relativamente estáveis de enunciados" (BAKHTIN, 2003, p. 279). Nessa perspectiva, cada gênero textual tem suas características específicas e são elaborados/modificados a partir de necessidades sociais.

Bakhtin (2003, p. 263) ao tratar sobre os diferentes gêneros discursivos, esclarece que esses podem ser de ordem primária ou secundária. A primeira refere-se àqueles gêneros constituídos em situações espontâneas. Suas características predominantes seriam o controle mútuo da situação, a imediatez do funcionamento do gênero e o pouco controle metalinguístico sobre a ação linguística em curso. Alguns exemplos que poderíamos tomar aqui seriam as conversas entre parentes próximos ao telefone, os bilhetes deixados sobre a mesa da sala, as mensagens instantâneas trocadas entre amigos na internet. Já os gêneros secundários seriam aqueles mais distantes de situações comunicativas cotidianas, pertencentes a contextos que exigiriam maior grau de formalidade, como, por exemplo, os discursos políticos, os debates entre pesquisadores, os artigos e relatórios científicos, as cartas de reclamação e solicitação, as instruções de montagem, entre outros.

É importante salientar que os gêneros primários e secundários não estão necessariamente relacionados à modalidade de 
funcionamento oral ou escrita. Tal classificação pauta-se, na verdade, no controle mais ou menos intenso da metalinguagem requerida em determinados contextos de produção. Assim, alguns gêneros orais que a princípio poderiam ser tomados como gêneros primários, exigem um gerenciamento metacognitivo da linguagem quase que constante, seu contexto geralmente requer preparações prévias, como é o caso de um discurso político. Esse, apesar da imediatez da situação em que o discurso será proferido e mesmo reconstituído, foi anteriormente preparado, pensado.

Para os gêneros escritos que poderiam, precipitadamente, serem considerados todos como gêneros secundários, temos os bilhetes e, atualmente, as mensagens instantâneas ou os "recados", deixados em páginas pessoais dispostas na internet. Esses estariam concentrados no grupo dos gêneros primários, devido a sua não-formalidade e mesmo a fluidez comunicativa, como a sua dependência diante do contexto comunicativo.

Sobre os gêneros secundários, o que se conclui é que necessitam de um ensino sistematizado para sua apropriação (SCHNEUWLY, 2004, p. 30- 33). Torna-se pertinente lembrar também que não há uma oposição entre o oral e o escrito, há níveis de relações entre as modalidades textuais que nos permitem identificar predominâncias e, além disso, há que se ressaltar a igualmente relevante presença dos recursos visuais na apresentação/produção desses. Para Dionísio (2011, p. 139), "os gêneros textuais orais e escritos são multimodais [...] a multimodalidade é um traço constitutivo do discurso oral e escrito", e essa característica se torna extremamente relevante ao voltarmos o nosso olhar para os aspectos verbais do texto e, em particular, para os gêneros textuais.

Dolz e Schneuwly (2004), ao refletirem sobre a importância desse conceito para a organização do ensino na escola básica, organizaram uma proposta para o ensino da língua que tem como eixo de reflexão os gêneros textuais. Tais autores, que sistematizaram uma progressão curricular para o ensino do Francês na Suíça Francófona, buscaram classificar alguns gêneros existentes em cinco ordens: narrar, relatar, expor, descrever ações, argumentar. Os autores advogam que as cinco ordens precisariam estar presentes desde os anos iniciais de escolarização, por meio de um currículo em espiral. As capacidades necessárias para as atividades de leitura e produção de textos desses gêneros seriam desenvolvidas pelos alunos gradativamente. A seleção 
v. 7 (2) 490-516 ago/dez 2017 dos textos a serem usados em sala de aula seria orientada pelo caráter que eles possuem, por sua finalidade e pelas capacidades de linguagem a serem apropriadas.

Apenas em busca de detalhar os agrupamentos propostos por Dolz e Schneuwly (2004a, p. 60-61), retomaremos as características globais para cada um deles, especificando o domínio social de comunicação, o aspecto tipológico e as capacidades de linguagem dominantes, assim como exemplos de gêneros, respectivamente:

1. Cultura literária ficcional - narrar - mimese da ação através da criação da intriga no domínio do verossímil - contos de fadas, contos maravilhosos, biografia romanceada, crônicas literárias, adivinhas, piadas;

2. Documentação e memorização das ações humanas - relatar - representação pelo discurso de experiências vividas, situadas no tempo - relatos de experiência, relatos de viagem, testemunhos, anedotas, autobiografias, curriculum vitae;

3. Transmissão e construção de saberes - expor - apresentação textual de diferentes formas dos saberes - texto expositivo (em livros didáticos), seminários, conferências, resenhas, verbete, palestras;

4. Instruções e prescrições - descrever ações - regulação mútua de comportamentos - instruções de montagem, receitas, regulamentos, regras de jogos;

5. Discussão de problemas sociais controversos - argumentar - sustentação, refutação e negociação de tomadas de posição - textos de opinião, carta do leitor, carta de reclamação e solicitação, debate regrado, assembleia, resenha crítica, artigos de opinião, editoriais (DOLZ; SCHNEUWLY, 2004a, p. 60-61).

Essa classificação é destinada a fins didáticos, tendo em vista que os textos agrupados em cada ordem são heterogêneos. Além disso, os agrupamentos não contemplam todos os textos que circulam em uma dada sociedade, sobretudo quando se considera que os gêneros são construções históricas e sociais. Ou seja, têm a possibilidade de desaparecer, reaparecer e modificar-se. Mesmo assim, é importante reconhecermos a importância dessa classificação, pois ela auxilia na difícil tarefa de delimitar o que ensinar e como ensinar. 
Apesar de termos certa concordância na literatura da área acerca da necessidade de diversificarmos os gêneros textuais na escola, algumas pesquisas apontam para a quase inexistência do trabalho com os gêneros da ordem do argumentar nos livros didáticos de Língua Portuguesa, enquanto os da ordem do narrar e do dissertar aparecem em quantidades consideráveis (SILVA, 1999; ANDRADE; LEAL; BRANDÃO, 2005). Numa pesquisa realizada por Silva (1999), em três coleções de livros didáticos de Língua Portuguesa de $5^{\mathrm{a}}$ a $8^{\mathrm{a}}$ série, foi identificado que, das várias ordens de texto, a que diz respeito à do argumentar é a que menos ganha espaço a ser trabalhado na sala de aula.

Aqui, exploraremos o resultado das análises de duas coleções de livros didáticos de História de $1^{\mathrm{a}}$ a $4^{\mathrm{a}}$ série do ensino fundamental com relação à variedade dos gêneros presentes nestas e observaremos quais as ordens mais ou menos contempladas em sua elaboração. Daremos destaque ao gênero discursivo que aparece de forma mais frequente em cada obra. Antes, porém, dissertaremos acerca dos critérios de escolha das obras e nossa orientação metodológica.

\section{Orientação Metodológica}

Adotamos a abordagem de cunho qualitativo e quantitativo. Qualitativo porque as obras analisadas foram investigadas de modo aprofundado, na busca de compreendermos a proposta pedagógica que estava subjacente ao material. Não obstante, também nos valemos da organização dos dados de acordo com a estatística descritiva, o que nos possibilitou um mapeamento do conjunto das ocorrências presentes nas coleções, pondo em destaque as de maior frequência.

Para a escolha das coleções, o primeiro critério se referia à aprovação no Programa Nacional do Livro Didático/2007 (PNLD/2007). Um segundo critério fez referência à adoção das obras pela rede pública municipal de ensino do Recife: uma das coleções analisadas foi a mais adotada nessa rede e a outra foi uma das menos adotadas. Nossa intenção era verificar se havia tendências diferentes, até mesmo opostas, de ensino-aprendizagem nas obras que justificassem sua maior ou menor adoção. Por isso, dentre as menos escolhidas, recorremos à que apresentasse uma organização dos conteúdos diferente da identificada como a mais aceita. Assim, a primeira coleção esteve caracterizada no Guia do PNLD/2007 de História como organizada por temas geradores, ou eixos temáticos, e a segunda por narrativas ficcionais. 
v. $7(2)$ 490-516 ago/dez 2017

Tratamos nossos dados de acordo com a análise de conteúdo, desenvolvida por Bardin (1977). Esta metodologia baseia-se em três momentos, a saber: a pré-análise, a exploração do material e o tratamento dos resultados. O primeiro representa o contato inicial estabelecido entre o pesquisador e as informações colhidas, a fim de superar as impressões pré-concebidas. Para atender a esse momento, o pesquisador lança mão da estratégia da leitura flutuante. Para o segundo, a autora alega que é a exploração propriamente dita do material, da qual surgem as classificações, codificações, a organização desses dados. Por fim, é no momento do tratamento dos dados que se produz as inferências advindas da triangulação entre os autores de referência e os dados colhidos.

\section{As coleções: características essenciais e variedade textual}

Abordaremos nossos achados acerca do material textual inserido em duas coleções de livros didático de História destinados aos anos iniciais do ensino fundamental ( $1^{\mathrm{a}}$ à $4^{\mathrm{a}}$ séries) aprovadas pelo Programa Nacional do Livro Didático (PNLD/MEC), denominadas coleção A e coleção B. Nossa pesquisa contou com dois momentos:

1. Análise dos textos presentes nos quatro volumes da coleção;

2. Categorização dos gêneros.

Para essa pesquisa, buscamos identificar os textos inseridos nos livros didáticos e classificá-los quanto aos gêneros discursivos, agrupando-os segundo as categorias propostas por Schneuwly e Dolz (2004) (textos da ordem do narrar, do relatar, do descrever ações, do expor e do argumentar) destinados à construção dos conhecimentos históricos.

O material textual encontrado foi categorizado de acordo com sua aproximação a um determinado gênero discursivo, considerandose a finalidade, o espaço de circulação e a forma composicional do texto. Mesmo que na obra fosse dada uma denominação para o gênero, esse era analisado e, muitas vezes, classificado com uma terminologia diferente da apontada, em função dos critérios estabelecidos para categorização. Esse percurso possibilitou identificar a validade da denominação usada no livro e considerar as dificuldades de classificação dos gêneros que foram adaptados para atender aos propósitos da obra e aos destinatários 
e dos que foram recortados (textos fragmentados). A dificuldade de categorizar os gêneros já fora ressaltada por outros pesquisadores:

A categorização dos gêneros se mostra complexa mesmo a uma abordagem mais sofisticada da categorização como a de Lakoff $(1987,1988)$. Os fenômenos que o autor aborda estão no âmbito da cultura, mas, ainda assim, contando com uma certa estabilidade terminológica e semântica.

No caso da categorização dos gêneros, o enfoque de categorização é interno ao próprio processo comunicativo, o que faz com que os critérios de agrupamento sejam bastante frouxos e interrelacionados. (BONINI, 2002, p. 136).

Uma das justificativas para essa dificuldade se fundamenta no fato dos gêneros discursivos serem "tipos relativamente estáveis de enunciados" (BAKHTIN, 2003, p. 262), que se modificam de acordo com o contexto histórico e social em que são produzidos e à finalidade a que se prestam. Muitos dos gêneros encontrados eram próximo daqueles dos quais receberam a nomenclatura, a rotulação, como as biografias, mas bastava um olhar um pouco mais aprofundado para identificarmos adaptações na linguagem ou nos conteúdos apresentados pelos gêneros numa tentativa de adequação aos usuários finais do material: os alunos. Esse percurso adaptativo deu origem a uma série de hibridismos e mimeses textuais que aqui serão revelados.

A primeira obra que recebeu por título "coleção A" foi representada pelo "Projeto Pitanguá", da editora Moderna. Sua autoria não é revelada na capa dos seus livros, nem o é no Guia do PNLD. Nas referências inseridas na contracapa da coleção, foi possível identificar uma equipe de autores: Maria Raquel Apolinário, Vitória Rodrigues e Silva, Letícia Fagundes de Oliveira, Maria Aparecida Jacomini e Sônia Cunha de Souza. Também é indicado o responsável pela editoração dos componentes do livro como tratamento de imagem, capa, revisão, pesquisa iconográfica, dentre outros. A segunda coleção, a obra "História", da série Brasil, editora Ática, de autoria de Maria Aparecida Lima Dias foi a segunda coleção escolhida. Destaque-se que a primeira coleção tem seus conteúdos organizados por meio de temáticas, rompendo com a perspectiva de trabalho da História cronológica linear. A segunda coleção igualmente rompe com essa orientação tradicional, mas, diferentemente da primeira, orienta a organização dos conteúdos por narrativas ficcionais. Essa informação se faz relevante à medida que se pretende destacar as escolhas discursivas de cada obra. 
v. $7(2)$ 490-516 ago/dez 2017

Inicialmente, daremos ênfase ao material textual apresentado pela coleção A com destaque ao gênero apresentado com maior frequência. Após, situaremos os dados relativos à coleção B. Por fim, nossas considerações voltam-se aos contrapontos das coleções.

\section{Coleção A: prioridades na seleção dos gêneros discursivos}

Os livros didáticos analisados são organizados por unidades que contêm textos variados. Esses textos têm status diferenciados na obra: ora são textos principais, ora complementares. Os textos destinados ao tratamento dos conteúdos são denominados de textos principais. Os que apresentam informações consideradas complementares, impressas geralmente em boxes separados do texto principal, são os complementares. As obras buscam também inserir ilustrações nas quais há imagens de textos retirados de outras esferas de circulação, como propagandas de revistas.

Ganha destaque na obra a grande quantidade e variedade de gêneros. Vale salientar que os gêneros que obtiveram maior representação detêm sozinhos - em seis categorias - mais de $60 \%$ do quantitativo apresentado, restando pouco menos de $40 \%$ distribuídos entre cerca de 50 categorias de outros gêneros. O mesmo acontece para os textos com dimensão argumentativa, que concentram mais de $70 \%$ de sua presença em apenas três gêneros. Detalhemos então esses dados.

Encontramos um total de 1.131 textos nessa coleção, para os quais 203 foram destinados ao primeiro volume, 250 ao segundo volume. O terceiro volume contou com o maior quantitativo da coleção, representado por 345 textos. No quarto volume foram inseridos 333 textos.

Nessa coleção foram encontrados 57 gêneros discursivos, com ocorrência de cerca de 33 gêneros por volume. Isto é, se supõe que a cada ano os alunos teriam garantido o contato com essa variedade textual. Isso não significa afirmar que o percentual de ocorrências foi distribuída de forma equânime. As legendas se sobressaem quanto à presença na coleção, seguidas pelo texto didático, glossário e relato histórico, que concentram mais de $65 \%$ do total, seguidos dos mapas e relatos pessoais/depoimentos. Os demais gêneros apresentaram menos de 20 ocorrências, o que contabiliza menos de $2 \%$ de frequência para cada (Tabela 1). 
Tabela 1 - Gêneros discursivos na Coleção A

\begin{tabular}{|c|c|c|c|c|c|c|c|c|c|c|}
\hline \multirow{2}{*}{ GÊNERO } & \multicolumn{2}{|c|}{ LD1 } & \multicolumn{2}{|c|}{ LD2 } & \multicolumn{2}{|c|}{ LD3 } & \multicolumn{2}{|c|}{ LD4 } & \multicolumn{2}{|c|}{ Total } \\
\hline & Freq. & $\%$ & Freq. & $\%$ & Freq. & $\%$ & Freq. & $\%$ & Freq. & $\%$ \\
\hline Legendas & 87 & 42,86 & 135 & 54,00 & 186 & 53,91 & 154 & 46,24 & 562 & 49,69 \\
\hline Texto didático & 42 & 20,69 & 39 & 15,60 & 45 & 13,04 & 52 & 15,61 & 178 & 15,73 \\
\hline Glossário & 12 & 5,92 & 8 & 3,20 & 26 & 7,53 & 21 & 6,30 & 67 & 5,92 \\
\hline $\begin{array}{l}\text { Relato } \\
\text { histórico }\end{array}$ & 5 & 2,46 & 12 & 4,80 & 23 & 6,66 & 17 & 5,10 & 57 & 5,04 \\
\hline Mapas & 3 & 1,50 & 11 & 4,40 & 20 & 5,79 & 15 & 4,50 & 49 & 4,33 \\
\hline $\begin{array}{l}\text { Relato } \\
\text { pessoal/ } \\
\text { depoimento }\end{array}$ & 10 & 4,94 & 4 & 1,60 & 8 & 2,33 & 6 & 1,80 & 28 & 2,47 \\
\hline $\begin{array}{l}\text { Notas } \\
\text { informativas }\end{array}$ & 5 & 2,46 & 4 & 1,60 & 4 & 1,16 & 5 & 1,50 & 18 & 1,59 \\
\hline $\begin{array}{l}\text { Biografias/ } \\
\text { notas } \\
\text { biográficas }\end{array}$ & 9 & 4,43 & 3 & 1,20 & 1 & 0,29 & 3 & 0,26 & 16 & 1,41 \\
\hline Músicas & 2 & 0,99 & 4 & 1,60 & 4 & 1,15 & 6 & 1,80 & 16 & 1,41 \\
\hline Gráficos & 0 & 0 & 4 & 1,60 & 5 & 1,45 & 4 & 1,20 & 13 & 1,14 \\
\hline Poemas & 7 & 3,44 & 4 & 1,60 & 1 & 0,29 & 0 & 0 & 12 & 1,06 \\
\hline Apresentação & 1 & 0,49 & 2 & 0,80 & 3 & 0,87 & 3 & 0,90 & 9 & 0,79 \\
\hline Tabela & 0 & 0 & 0 & 0 & 0 & 0 & 9 & 2,70 & 9 & 0,79 \\
\hline Conto & 1 & 0,49 & 2 & 0,80 & 2 & 0,58 & 3 & 0,90 & 8 & 0,70 \\
\hline $\begin{array}{l}\text { Linha do } \\
\text { tempo }\end{array}$ & 1 & 0,49 & 2 & 0,80 & 0 & 0 & 4 & 1,20 & 7 & 0,61 \\
\hline Enigma & 0 & 0 & 6 & 2,40 & 0 & 0 & 0 & 0 & 6 & 0,53 \\
\hline Propaganda & 1 & 0,49 & 1 & 0,40 & 0 & 0 & 4 & 1,20 & 6 & 0,53 \\
\hline Capa de livro & 1 & 0,49 & 0 & 0 & 2 & 0,58 & 2 & 0,60 & 5 & 0,44 \\
\hline Diálogos & 1 & 0,49 & 2 & 0,80 & 0 & 0 & 2 & 0,60 & 5 & 0,44 \\
\hline $\begin{array}{l}\text { Artigo de } \\
\text { lei/leis/ } \\
\text { constituição }\end{array}$ & 2 & 0,99 & 0 & 0 & 0 & 0 & 2 & 0,60 & 4 & 0,35 \\
\hline Quadro & 1 & 0,49 & 1 & 0,40 & 0 & 0 & 2 & 0,60 & 4 & 0,35 \\
\hline $\begin{array}{l}\text { Cantiga } \\
\text { popular/ } \\
\text { canções }\end{array}$ & 0 & 0 & 1 & 0,40 & 1 & 0,29 & 1 & 0,30 & 3 & 0,27 \\
\hline Charge & 0 & 0 & 0 & 0 & 0 & 0 & 3 & 0,90 & 3 & 0,27 \\
\hline Cordel & 0 & 0 & 0 & 0 & 0 & 0 & 3 & 0,90 & 3 & 0,27 \\
\hline Reportagem & 2 & 0,99 & 0 & 0 & 1 & 0,29 & 0 & 0 & 3 & 0,27 \\
\hline Tirinha & 1 & 0,49 & 0 & 0 & 1 & 0,29 & 1 & 0,30 & 3 & 0,27 \\
\hline $\begin{array}{l}\text { Convocação/ } \\
\text { Cartaz de } \\
\text { convocação }\end{array}$ & 0 & 0 & 0 & 0 & 1 & 0,29 & 2 & 0,60 & 3 & 0,27 \\
\hline
\end{tabular}


Gêneros textuais em livros didáticos...

v. 7 (2)

490-516

ago/dez

2017

\begin{tabular}{|c|c|c|c|c|c|c|c|c|c|c|}
\hline $\begin{array}{l}\text { Capa de } \\
\text { partitura }\end{array}$ & 0 & 0 & 0 & 0 & 2 & 0,58 & 0 & 0 & 2 & 0,18 \\
\hline $\begin{array}{l}\text { Cartaz de } \\
\text { divulgação }\end{array}$ & 0 & 0 & 0 & 0 & 1 & 0,29 & 1 & 0,30 & 2 & 0,18 \\
\hline Crônica & 1 & 0,49 & 1 & 0,40 & 0 & 0 & 0 & 0 & 2 & 0,18 \\
\hline Esquema & 1 & 0,49 & 0 & 0 & 0 & 0 & 1 & 0,30 & 2 & 0,18 \\
\hline $\begin{array}{l}\text { Primeira } \\
\text { página de } \\
\text { jornal }\end{array}$ & 0 & 0 & 0 & 0 & 1 & 0,29 & 1 & 0,30 & 2 & 0,18 \\
\hline Anúncio & 1 & 0,49 & 0 & 0 & 0 & 0 & 0 & 0 & 1 & 0,09 \\
\hline $\begin{array}{l}\text { Artigos de } \\
\text { opinião }\end{array}$ & 0 & 0 & 0 & 0 & 0 & 0 & 1 & 0,30 & 1 & 0,09 \\
\hline Calendário & 1 & 0,49 & 0 & 0 & 0 & 0 & 0 & 0 & 1 & 0,09 \\
\hline $\begin{array}{l}\text { Capa de } \\
\text { revista }\end{array}$ & 0 & 0 & 0 & 0 & 1 & 0,29 & 0 & 0 & 1 & 0,09 \\
\hline $\begin{array}{l}\text { Cartaz } \\
\text { educativo }\end{array}$ & 1 & 0,49 & 0 & 0 & 0 & 0 & 0 & 0 & 1 & 0,09 \\
\hline Confissão & 0 & 0 & 0 & 0 & 1 & 0,29 & 0 & 0 & 1 & 0,09 \\
\hline Conta de luz & 1 & 0,49 & 0 & 0 & 0 & 0 & 0 & 0 & 1 & 0,09 \\
\hline $\begin{array}{l}\text { Dicas de } \\
\text { segurança }\end{array}$ & 1 & 0,49 & 0 & 0 & 0 & 0 & 0 & 0 & 1 & 0,09 \\
\hline $\begin{array}{l}\text { Ditado } \\
\text { popular }\end{array}$ & 0 & 0 & 1 & 0,40 & 0 & 0 & 0 & 0 & 1 & 0,09 \\
\hline $\begin{array}{l}\text { Folder de } \\
\text { hospedaria }\end{array}$ & 0 & 0 & 0 & 0 & 1 & 0,29 & 0 & 0 & 1 & 0,09 \\
\hline $\begin{array}{l}\text { Folheto } \\
\text { publicitário }\end{array}$ & 0 & 0 & 0 & 0 & 1 & 0,29 & 0 & 0 & 1 & 0,09 \\
\hline Hino & 0 & 0 & 0 & 0 & 1 & 0,29 & 0 & 0 & 1 & 0,09 \\
\hline Lista & 0 & 0 & 0 & 0 & 0 & 0 & 1 & 0,30 & 1 & 0,09 \\
\hline $\begin{array}{l}\text { Nota de } \\
\text { enciclopédia }\end{array}$ & 0 & 0 & 0 & 0 & 1 & 0,29 & 0 & 0 & 1 & 0,09 \\
\hline Notícia & 0 & 0 & 1 & 0,40 & 0 & 0 & 0 & 0 & 1 & 0,09 \\
\hline $\begin{array}{l}\text { Página de } \\
\text { cartilha }\end{array}$ & 0 & 0 & 0 & 0 & 0 & 0 & 1 & 0,30 & 1 & 0,09 \\
\hline $\begin{array}{l}\text { Pôster de } \\
\text { filme }\end{array}$ & 0 & 0 & 0 & 0 & 1 & 0,29 & 0 & 0 & 1 & 0,09 \\
\hline $\begin{array}{l}\text { Regras de } \\
\text { jogos }\end{array}$ & 1 & 0,49 & 0 & 0 & 0 & 0 & 0 & 0 & 1 & 0,09 \\
\hline $\begin{array}{l}\text { Relato de } \\
\text { viagem }\end{array}$ & 0 & 0 & 1 & 0,40 & 0 & 0 & 0 & 0 & 1 & 0,09 \\
\hline Selo & 0 & 0 & 0 & 0 & 0 & 0 & 1 & 0,30 & 1 & 0,09 \\
\hline $\begin{array}{l}\text { Nota } \\
\text { comemorativa }\end{array}$ & 0 & 0 & 0 & 0 & 0 & 0 & 1 & 0,30 & 1 & 0,09 \\
\hline
\end{tabular}




\begin{tabular}{|l|l|l|l|l|l|l|l|l|l|l|}
\hline $\begin{array}{l}\text { Capa da } \\
\text { Carteira de } \\
\text { Trabalho }\end{array}$ & 1 & 0,49 & 0 & 0 & 0 & 0 & 0 & 0 & 1 & 0,09 \\
\hline $\begin{array}{l}\text { Artigo } \\
\text { científico }\end{array}$ & 0 & 0 & 1 & 0,40 & 0 & 0 & 0 & 0 & 1 & 0,09 \\
\hline Fotografia ${ }^{1}$ & 0 & 0 & 0 & 0 & 0 & 0 & 1 & 0,30 & 1 & 0,09 \\
\hline Total & 203 & 99,99 & 250 & 100 & 345 & 99,99 & 333 & 100 & 1131 & 100,0 \\
\hline
\end{tabular}

Passemos, então, à análise dos gêneros mais frequentes apresentados na coleção. Desses, como pudemos constatar, os que obtiveram maior frequência foram: legendas, glossários, relatos históricos e também os textos didáticos.

O primeiro gênero a ser destacado, que assumiu quase 50\% do total das ocorrências na obra, foram as legendas. Em relação a esses, os pareceristas do PLND salientam:

Nesta coleção, com raras exceções, há correção na forma de identificar a iconografia apresentada mediante informações corretas e completas nas legendas que contextualizam a imagem e a vinculam ao tema e ao texto. (BRASIL, 2006, p. 163).

As legendas assumiram presença marcante. Predominantemente compostas por frases curtas, tinham por finalidade contextualizar imagens dispostas - de outros textos, tais como pinturas, monumentos - de forma a disponibilizar aos alunos informações como autoria, títulos ou apresentar as imagens aos/às discentes, em geral, citando a obra ou descrevendo o que estava à mostra na ilustração. Abaixo exemplificamos as duas funções identificadas.

Figura 1 - Legenda 1

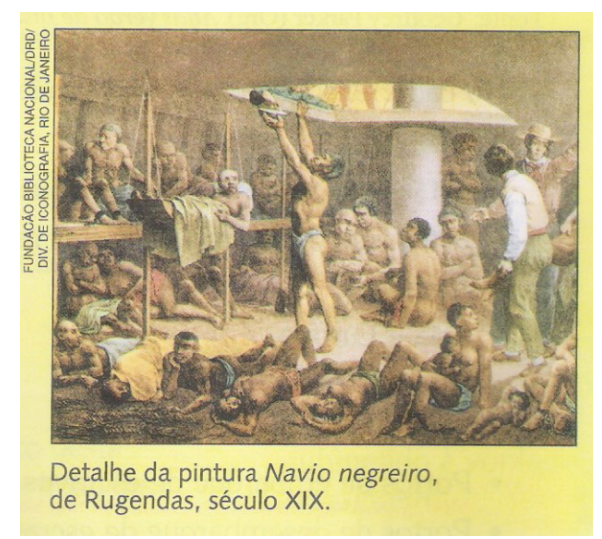

Fonte: Coleção A, volume 3, p. 49.

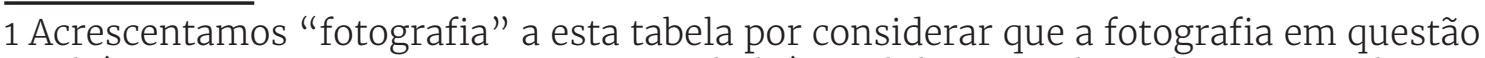
também se apresenta como um texto verbal, à medida que nela podemos visualizar a figura de uma criança segurando um cartaz. 
v. 7 (2) 490-516 ago/dez

\section{7}

Figura 2 - Legenda 2

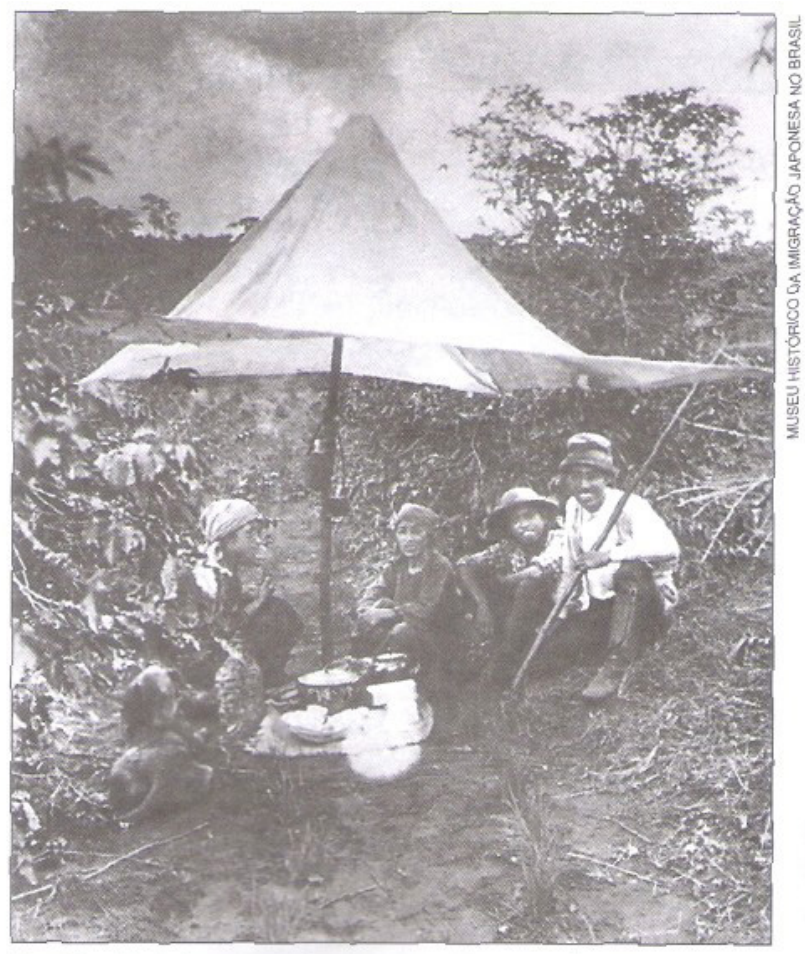

Família de imigrantes japoneses almoçando em cafezal paulista, cerca de 1930.

Fonte: Coleção A, volume 3, p. 90.

502

Figura 3 - Legenda 3

Capitão-do-mato, gravura de Rugendas, de 1835. Em troca de recompensas, os capitães-do-mato saíam em busca de escravos fugitivos.

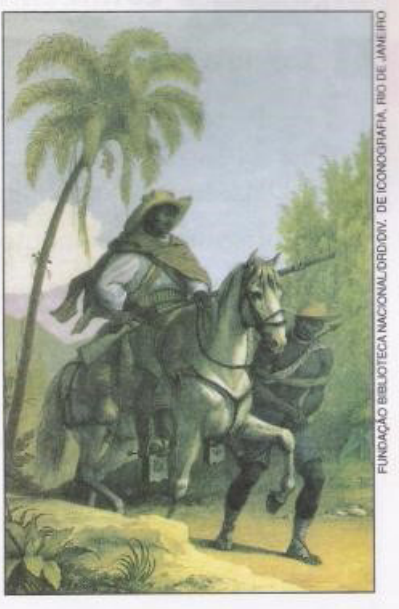

Fonte: Coleção A, volume 3, p. 121.

Diferentes funções puderam ser atribuídas às legendas nos livros didáticos. Por diversos momentos apareciam conjugadas, não havendo, assim, limites definidos entre elas. Algumas vezes, por exemplo, as legendas destinavam-se a apresentar a imagem, porém, essas estavam inseridas em exercícios de compreensão textual que as levavam a assumir também um papel de problematização, como em atividades de comparação entre imagens e textos das legendas. 
Consideramos que a presença das legendas foi significativa, atingindo a perspectiva de contribuir para contextualização, bem como a apresentação de textos verbais e não verbais nos livros. Por outro lado, a sua percentagem atinge níveis tão superiores em relação a outros gêneros que levavam a questionar a pertinência desse quantitativo. É bem verdade que, como são textos muito curtos, ocupam menos espaço. A quantidade bastante significativa desses gêneros pode representar uma preocupação em torno de inserir as imagens de forma a identificálas e/ou contextualizá-las.

No caso dos textos didáticos, em muitas situações assemelhavamse a "relatos históricos" quando retomavam pesquisas historiográficas acerca de determinado acontecimento histórico ou quando se propunham a explicar historicamente a ocorrência de fenômenos sociais. No entanto, quando tais situações se apresentavam, a finalidade proposta para o momento era levar o aluno ao conhecimento de conteúdos basilares da disciplina e do que se estava discutindo. Portanto, foram, na maior parte das vezes, classificados como textos didáticos por se tratarem de textos adaptados ou, na grande maioria, de produção da própria autoria da coleção.

A variação das finalidades dos textos ou os gêneros a que pertencem não demonstrou ser a orientação central utilizada pela coleção para selecionar/organizar seus mais de mil textos. Para assunção do papel de texto principal, foram utilizados os textos didáticos ou relatos históricos, gêneros para os quais o tratamento dos conteúdos históricos escolares destinaram-se quase que exclusivamente. Para figurar como "ilustrações", alguns textos que serviram como "fontes históricas" ganharam espaço ao redor, às margens do que seria o texto principal, como foi o caso das capas de revistas, propagandas, primeiras páginas de jornal, entre outros. As legendas aparecem executando funções explicativas ou contextualizando as imagens (pinturas, fotografias, desenhos, objetos) e os textos que serviam de documentos históricos. "Costurando" todos esses textos, aparecem textos com caráter complementar: biografias, reportagens, notícias, entre outros. Ou seja, mesmo apresentando os gêneros oriundos de contextos autênticos, a coleção não elege como prioridade um trabalho sistematizado que leve os alunos a explorá-los como fonte histórica ou como objeto de reflexão sobre a realidade. Há que se ressaltar que nossa afirmativa pauta-se também no fato de que a maioria desses "textos documentos históricos" ou "textos ilustração/complemento" realizou-se através de fragmentos, recortes do gênero, o que poderia impossibilitar os alunos a ter acesso à totalidade do texto via livro didático. 
v. 7 (2) 490-516 ago/dez 2017

Se pensarmos na proposta de progressão curricular dos gêneros elaborada por Schneuwly e Dolz (2004), teríamos mais uma constatação: o livro estaria limitando, no que diz respeito a esse material específico - o livro didático de história ${ }^{2}$, o acesso dos alunos a textos que lhe exigiriam o desenvolvimento, a compreensão de diversas capacidades linguísticas. Por exemplo, encontramos poucos textos pertencentes aos agrupamentos descrever ações, narrar e argumentar, em prol de uma presença mais marcante daqueles que poderiam ser agrupados nas ordens do expor e relatar. Essas duas últimas ordens contabilizaram cerca de $25 \%$ dos textos, concentrando-se nos textos didáticos, relatos históricos, biografias e relatos de viagem. Já as três primeiras somaram menos de $5 \%$ do total de ocorrências, diluídas em uma série de gêneros: crônicas, contos, charges, propagandas, anúncios, cartazes de convocação e educativos, reportagens, notícias, regras de jogos, entre outros. Além desses, é importante considerar que a maior frequência constatada pela presença dos gêneros na coleção não esteve alocada em nenhuma das categorias propostas por Schneuwly e Dolz (2004), sobretudo quando se considera o percentual impresso pelas legendas. Nesse conjunto de "outras ordens" estariam também situados

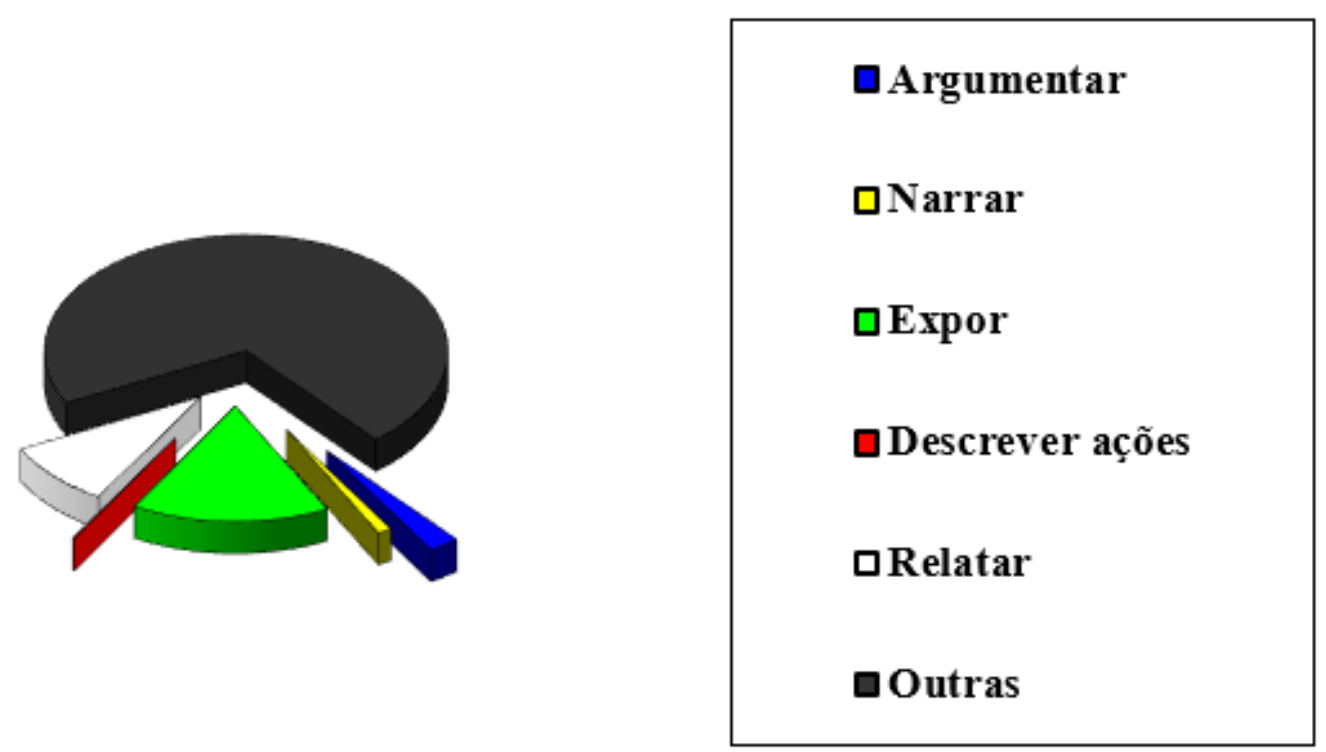
os gêneros como músicas, poesias, glossários e
de $70 \%$, como pode ser visualizado no Gráfico 1.

Gráfico 1 - Agrupamentos de textos contemplados na coleção A

\footnotetext{
${ }^{2}$ Não podemos deixar de considerar que os alunos possuem um contato amplo com as diversas ordens de textos nas demais disciplinas escolares e, diríamos aqui principalmente, no espaço extraescolar. Entretanto, o que está em jogo são conhecimentos linguísticos que poderiam ser melhor apropriados pelos alunos através de um trabalho sistematizado possibilitado na escola, nas relações de ensinoaprendizagem com colegas, professores e materiais didáticos. Nesse caso, o livro didático de História.
} 
Essa constatação nos leva a inferir que, no contato com a coleção A, é mais provável que os alunos se aproximassem melhor das funções do que foi denominado de legendas, relatos históricos e textos didáticos - dos quais grande parcela destes foi adaptada - que dos artigos de opinião, reportagens, notícias. Esses, além de contarem com uma presença pouco significativa, ainda foram usados como textos complementares ou ilustrações. Sigamos, agora, com a análise referente à coleção B.

\section{Coleção B: seleção textual e trabalho com os gêneros discursivo}

Inicialmente, nos centraremos na abordagem dos gêneros mais frequentes na coleção B. Desses, mapearemos quais os que possuíam dimensão argumentativa. Entretanto, antes é preciso fazer algumas considerações. As descobertas acerca do material textual da coleção B apontam para uma perspectiva contrária à proposta de linearização da história, impulsionando a obra para a escolha de outros gêneros para assumirem a função de textos principais e não apenas os relatos históricos. No entanto, houve uma forte presença de textos adaptados, traduzidos também na categoria de textos didáticos.

A coleção apresentou 720 textos, dos quais para o volume 1 foram destinados 161, para o volume 2 inseriram-se 134 textos. O volumes 3 e 4 apresentaram as maiores frequências com, respectivamente, 173 e 252. Esses foram distribuídos de forma não igualitária entre 42 gêneros, dos quais os mais frequentes foram novamente as legendas, textos didáticos e mapas, que concentraram cerca de $80 \%$ das ocorrências na coleção. A esses, seguiram-se as apresentações e o que se denominou de "objetivos" - destinados não à leitura para compreensão ou para apropriação dos conteúdos, mas para orientar/motivar/preparar os alunos aos assuntos abordados nos capítulos ou blocos - representantes de pouco mais de $7 \%$ da totalidade dos gêneros. Os cerca de $10 \%$ restantes foram distribuídos entre as mais de 30 categorias, nas quais estão aqueles pertencentes à ordem do argumentar (Tabela 2). 
Tabela 2 - Gêneros discursivos na Coleção B

\begin{tabular}{|c|c|c|c|c|c|c|c|c|c|c|}
\hline \multirow{2}{*}{ GÊNERO } & \multicolumn{2}{|c|}{ LD1 } & \multicolumn{2}{|c|}{ LD2 } & \multicolumn{2}{|c|}{ LD3 } & \multicolumn{2}{|c|}{ LD4 } & \multicolumn{2}{|c|}{ Total } \\
\hline & Freq. & $\%$ & Freq. & $\%$ & Freq. & $\%$ & Freq. & $\%$ & Freq. & $\%$ \\
\hline Legendas & 97 & 60,24 & 71 & 52,98 & 118 & 68,20 & 139 & 55,15 & 425 & 59,02 \\
\hline Texto didático & 31 & 19,25 & 17 & 12,68 & 26 & 15,03 & 38 & 15,07 & 112 & 15,54 \\
\hline Mapas & 4 & 2,48 & 6 & 4,47 & 9 & 5,20 & 10 & 3,96 & 29 & 4,02 \\
\hline $\begin{array}{l}\text { Apresentação/ } \\
\text { nota de } \\
\text { apresentação }\end{array}$ & 6 & 3,72 & 6 & 4,47 & 4 & 2,32 & 12 & 4,76 & 28 & 3,88 \\
\hline $\begin{array}{l}\text { Objetivos do } \\
\text { capítulo }\end{array}$ & 8 & 4,96 & 5 & 3,73 & 5 & 2,90 & 9 & 3,57 & 27 & 3,75 \\
\hline $\begin{array}{l}\text { Biografias/ } \\
\text { notas } \\
\text { biográficas }\end{array}$ & 3 & 1,89 & 3 & 2,23 & 0 & 0 & 3 & 1,19 & 9 & 1,25 \\
\hline Glossário & 1 & 0,63 & 5 & 3,73 & 1 & 0,58 & 1 & 0,39 & 8 & 1,11 \\
\hline Reportagem & 1 & 0,63 & 2 & 1,49 & 1 & 0,58 & 4 & 1,58 & 8 & 1,11 \\
\hline Notícia & 0 & 0 & 2 & 1,49 & 0 & 0 & 6 & 2,38 & 8 & 1,11 \\
\hline Lenda & 0 & 0 & 4 & 2,98 & 2 & 1,15 & 1 & 0,39 & 7 & 0,97 \\
\hline Conto & 4 & 2,48 & 0 & 0 & 2 & 1,15 & 0 & 0 & 6 & 0,83 \\
\hline Quadro & 0 & 0 & 0 & 0 & 1 & 0,58 & 4 & 1,58 & 5 & 0,69 \\
\hline $\begin{array}{l}\text { Propaganda/ } \\
\text { anúncio } \\
\text { publicitário }\end{array}$ & 0 & 0 & 0 & 0 & 0 & 0 & 4 & 1,58 & 4 & 0,55 \\
\hline $\begin{array}{l}\text { Relato } \\
\text { Histórico }\end{array}$ & 0 & 0 & 0 & 0 & 0 & 0 & 4 & 1,58 & 4 & 0,55 \\
\hline Regra de jogo & 3 & 1,89 & 0 & 0 & 0 & 0 & 0 & 0 & 3 & 0,42 \\
\hline $\begin{array}{l}\text { Notas } \\
\text { informativas }\end{array}$ & 0 & 0 & 0 & 0 & 1 & 0,58 & 2 & 0,78 & 3 & 0,42 \\
\hline Tabela & 0 & 0 & 0 & 0 & 0 & 0 & 3 & 1,19 & 3 & 0,42 \\
\hline Músicas & 0 & 0 & 0 & 0 & 0 & 0 & 2 & 0,78 & 2 & 0,27 \\
\hline Receita & 2 & 1,25 & 0 & 0 & 0 & 0 & 0 & 0 & 2 & 0,27 \\
\hline Anúncio & 0 & 0 & 0 & 0 & 0 & 0 & 2 & 0,78 & 2 & 0,27 \\
\hline Capa de revista & 0 & 0 & 0 & 0 & 0 & 0 & 2 & 0,78 & 2 & 0,27 \\
\hline Calendário & 0 & 0 & 0 & 0 & 2 & 1,15 & 0 & 0 & 2 & 0,27 \\
\hline Texto bíblico & 0 & 0 & 2 & 1,49 & 0 & 0 & 0 & 0 & 2 & 0,27 \\
\hline Diálogos & 0 & 0 & 0 & 0 & 0 & 0 & 1 & 0,39 & 1 & 0,13 \\
\hline Esquema & 0 & 0 & 0 & 0 & 0 & 0 & 1 & 0,39 & 1 & 0,13 \\
\hline $\begin{array}{l}\text { Cartaz de } \\
\text { convocação }\end{array}$ & 0 & 0 & 0 & 0 & 0 & 0 & 1 & 0,39 & 1 & 0,13 \\
\hline Lista & 1 & 0,63 & 0 & 0 & 0 & 0 & 0 & 0 & 1 & 0,13 \\
\hline $\begin{array}{l}\text { Caderneta do } \\
\text { pezinho }\end{array}$ & 0 & 0 & 1 & 0,75 & 0 & 0 & 0 & 0 & 1 & 0,13 \\
\hline
\end{tabular}




\begin{tabular}{|l|l|l|l|l|l|l|l|l|l|l|}
\hline $\begin{array}{l}\text { Certidão de } \\
\text { nascimento }\end{array}$ & 0 & 0 & 1 & 0,75 & 0 & 0 & 0 & 0 & 1 & 0,13 \\
\hline RG & 0 & 0 & 1 & 0,75 & 0 & 0 & 0 & 0 & 1 & 0,13 \\
\hline CPF & 0 & 0 & 1 & 0,75 & 0 & 0 & 0 & 0 & 1 & 0,13 \\
\hline $\begin{array}{l}\text { Título de } \\
\text { eleitor }\end{array}$ & 0 & 0 & 1 & 0,75 & 0 & 0 & 0 & 0 & 1 & 0,13 \\
\hline $\begin{array}{l}\text { Carteira de } \\
\text { vacinação }\end{array}$ & 0 & 0 & 1 & 0,75 & 0 & 0 & 0 & 0 & 1 & 0,13 \\
\hline CTPS & 0 & 0 & 1 & 0,75 & 0 & 0 & 0 & 0 & 1 & 0,13 \\
\hline Passaporte & 0 & 0 & 1 & 0,75 & 0 & 0 & 0 & 0 & 1 & 0,13 \\
\hline $\begin{array}{l}\text { Certificado de } \\
\text { reservista }\end{array}$ & 0 & 0 & 1 & 0,75 & 0 & 0 & 0 & 0 & 1 & 0,13 \\
\hline $\begin{array}{l}\text { Carteira de } \\
\text { habilitação }\end{array}$ & 0 & 0 & 1 & 0,75 & 0 & 0 & 0 & 0 & 1 & 0,13 \\
\hline $\begin{array}{l}\text { Nota de } \\
\text { enciclopédia }\end{array}$ & 0 & 0 & 1 & 0,75 & 0 & 0 & 0 & 0 & 1 & 0,13 \\
\hline Entrevista & 0 & 0 & 0 & 0 & 0 & 0 & 1 & 0,39 & 1 & 0,13 \\
\hline Planta baixa & 0 & 0 & 0 & 0 & 0 & 0 & 1 & 0,39 & 1 & 0,13 \\
\hline $\begin{array}{l}\text { Instrução de } \\
\text { montagem }\end{array}$ & 0 & 0 & 0 & 0 & 0 & 0 & 1 & 0,39 & 1 & 0,13 \\
\hline $\begin{array}{l}\text { Relato de } \\
\text { viagem }\end{array}$ & 0 & 0 & 0 & 0 & 1 & 0,58 & 0 & 0 & 1 & 0,13 \\
\hline Total & 161 & 100 & 134 & 99,99 & 173 & 100 & 252 & 100 & 720 & 100,00 \\
\hline
\end{tabular}

A coleção B apresenta um enorme percentual de presença das legendas. Também essas são destacadas pelos avaliadores do Programa Nacional do Livro Didático no que diz respeito ao seu uso no livro: "Com legendas, contextualiza e explica adequadamente as obras reproduzidas, identificando o autor, o local e a época retratados" (BRASIL, 2006, p. 88).

Nessa coleção, encontramos a presença de legendas que apresentavam e contextualizavam as imagens dispostas. Em muitos exercícios essas eram levadas à problematização. A seguir, é possível acessar as funções assumidas pelo gênero: 
v. 7 (2) 490-516 ago/dez 2017

Figura 4 - Legenda 4

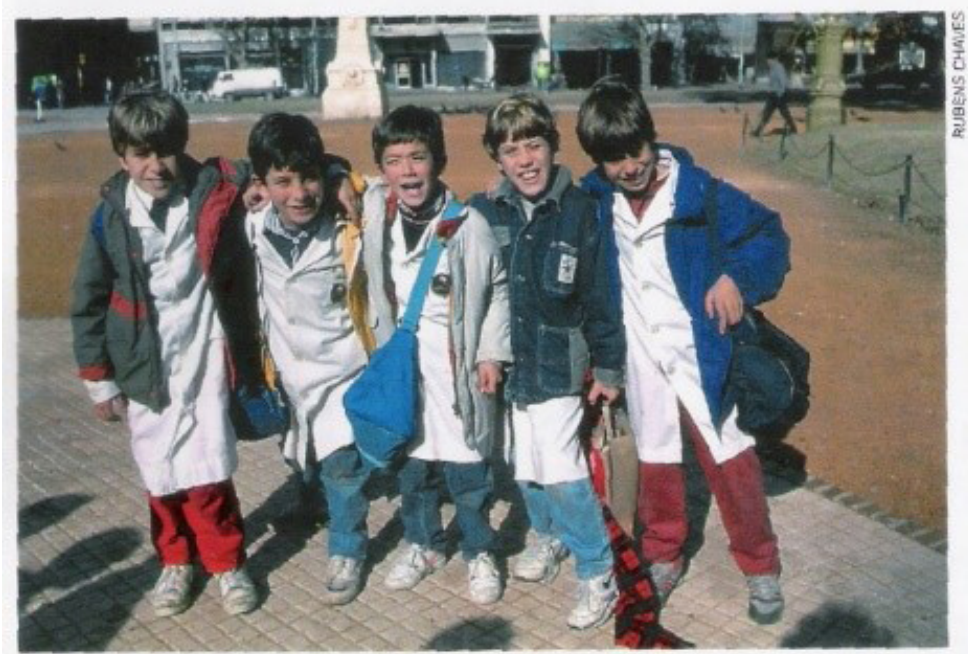

Meninos em Buenos Aires, Argentina.

Fonte: Coleção B, volume 3, p. 14.

Figura 5 - Legenda 5

Descendente maia trabalhando em tear

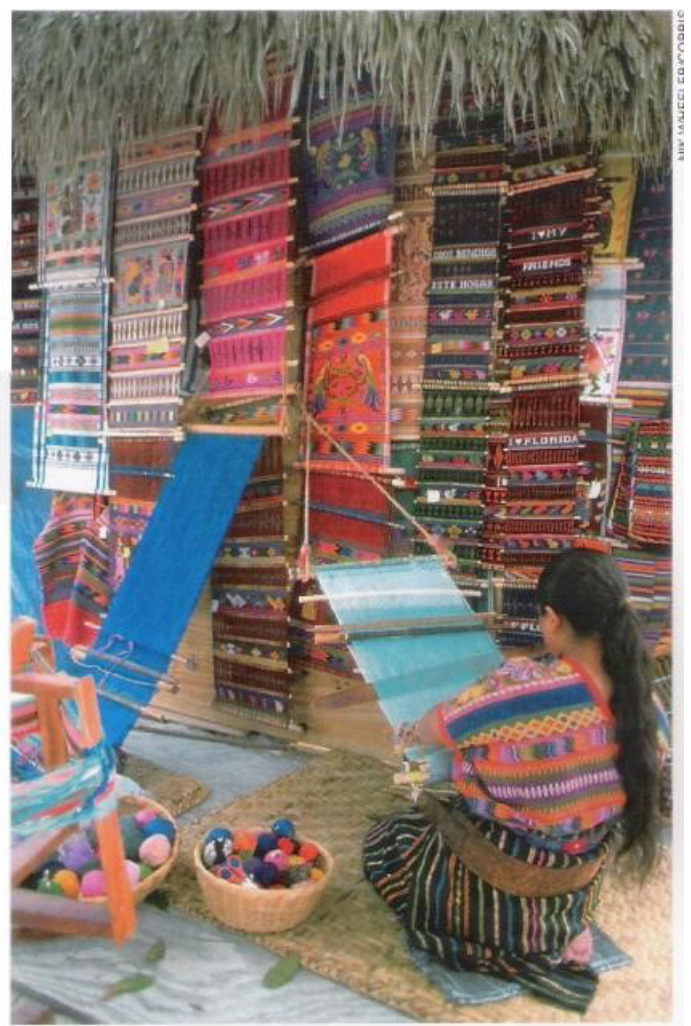

Fonte: Coleção B, volume 3, p. 39. 
Figura 6 - Legenda 6

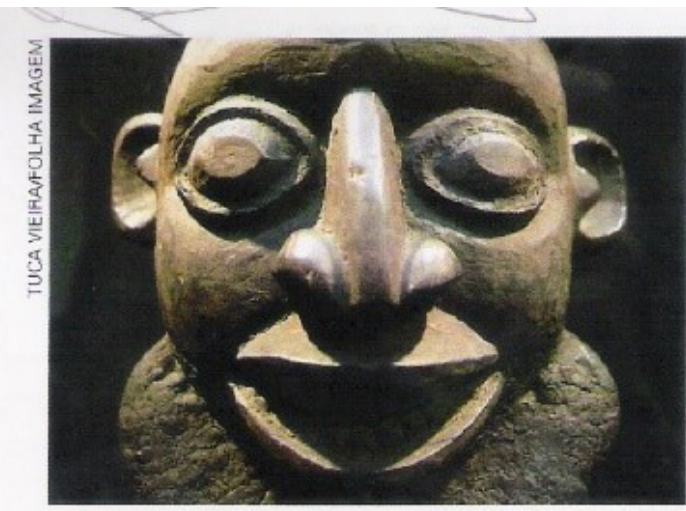

Máscara de madeira feita no século XIX usada pelo chefe da aldeia. Essa peça foi encontrada na região dos Camarões.

Fonte: Coleção B, volume 4, p. 82.

Nesses casos é possível observar que as legendas buscam situar as imagens ou chegam a descrever as ações por elas representadas. $\mathrm{Na}$ figura 6, além de apresentar a imagem, a legenda também se pretende explicativa, ao indicar outras informações do tipo ano de produção do objeto, sua função, local onde foi encontrado, etc. Portanto, desempenhando uma finalidade contextualizadora.

Em diversos exercícios, como afirmado, essas legendas eram problematizadas. Nesses casos, para além dessas funções indicadas, elas também eram destinadas a comparar informações.

Em linhas gerais, sobre o conjunto do material textual da coleção B (Tabela 2), a variedade ficou por conta de seus 42 gêneros, dos quais as oito primeiras categorias da tabela concentram mais de $80 \%$ dos textos da coleção. Esse dado nos é representativo do fenômeno da adaptação do material textual da coleção. O privilégio da inserção de textos oriundos de esferas extraescolares se faz através desse recurso. Ou seja, mesmo nos casos nos quais há a citação de fontes, com suas exceções, a opção é por adaptar o texto. Inclusive nos volumes houve a sensibilidade de informar a fonte e de indicar que texto fora adaptado. Nesse sentido, encontramos poucos fragmentos, mas muitas adaptações realizadas em gêneros como reportagens, contos, mapas, textos (tornados) didáticos, textos bíblicos, lendas, entre outros.

A finalidade de adaptar gêneros como lendas, textos bíblicos e contos nessa coleção parece ter surgido da adoção desses como textos 
v. 7 (2)

490-516 ago/dez 2017

principais na obra. Destaque-se que apenas 4 (0,55\%) do total dos gêneros que estamos chamando de relatos históricos aparecem na obra, somente no último volume, representados por fragmentos. Isso nos surpreende por que, historicamente, os livros didáticos de História estiveram marcados por sua narrativa linear e factual impressa nos relatos históricos, como é confirmado por Rosa e Brescó (2007, p. 167):

É muito comum que a maioria dos conhecimentos históricos de que dispomos provenham de textos escritos em forma narrativa, como também o é que os manuais de história utilizados para o ensino ofereçam narrações de acontecimentos do passado.

Romper com a perspectiva de uma cronologia linear e factual dessa História, denominada tradicional pelos especialistas, não significaria, necessariamente, romper com o uso do relato histórico nos materiais ou aulas da disciplina. Deixar de utilizar esse gênero não se resume a compartilhar perspectivas inovadoras. Mas essa parece ser a intenção alocada na obra. Isso também não se traduz em afirmar possível fuga desse material ao seu objetivo de trabalhar conteúdos históricos escolares. Ao contrário, as fontes para o trato desses parecem tentar seguir os ditames do PNLD quando requerem na ficha avaliação a adoção das inovações da área pedagógica e das renovações historiográficas (BRASIL, 2006, p. 25-27).

Na coleção é possível perceber o tratamento de temáticas provenientes eminentemente da historiografia, tais como: a História Medieval, a História dos povos da América Latina (Maias, Astecas, Incas e indígenas brasileiros), a origem da espécie humana e dos povos Americanos, História dos povos africanos e afrobrasileiros.

Quanto ao atendimento aos gêneros apresentados pelos agrupamentos propostos por Dolz e Schneuwly (2004a, p. 61), é possível perceber no Gráfico 2 que as ordens menos contempladas foram a do relatar, narrar, descrever ações e argumentar. Juntas essas chegam a somar pouco mais de $8 \%$. A ordem do expor é privilegiada na coleção, com cerca de $15 \%$. Contudo, a maior parte dos gêneros inclusos na coleção não se refere a nenhuma das ordens indicadas pelos autores. Essa concentrou mais de $75 \%$ dos textos. 
Gráfico 2 - Agrupamentos de textos contemplados na coleção B

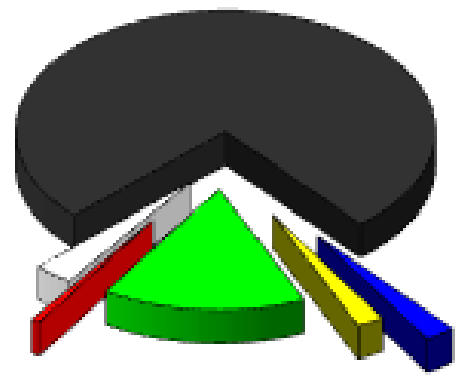

argumentar

口Narrar

口Expor

$\square$ Descrever ações

Delatar

口Outras

Em resumo, a coleção $B$ escolhe um recorte temático para abordar seus conteúdos. Essa opção fez com que, diante do material textual selecionado para compor seu corpus, o relato histórico não fosse tomado por objeto de análise e utilização, possivelmente por ser relacionado à perspectiva da história linear. Esta característica leva a coleção a concentrar o tratamento dos conteúdos através dos textos didáticos, permeados pelas legendas. Algumas vezes, esses eram intercalados por lendas, contos, receitas e outros. É necessário tecer algumas reflexões quanto aos dados surgidos dessas análises no que tange à escolha das obras. A seguir, teceremos considerações sobre as adaptações e fragmentos nesse processo de seleção textual.

\section{Adaptação e fragmentos: consequências na distribuição dos gêneros}

Após a análise de cada coleção, chegamos a uma constatação em comum: ambas demonstraram preocupação de variar os gêneros. Iniciativa essa que fica a desejar à medida que grande parte dessa variedade é prejudicada quando opta-se pela adaptação de vários daqueles gêneros oriundos de esferas extraescolares, e não pelo trabalho com os textos tal como se apresentam na sociedade, bem como pela preferência por incluir fragmentos desses gêneros. Essas duas formas de tratar os textos minimizam as possibilidades de análise por parte dos discentes, ao mesmo tempo em que restringem o seu espaço de letramento na não observância dos diversos usos e funções que assumem os gêneros. 
v. 7 (2) 490-516 ago/dez 2017

As adaptações e recortes dos textos foram observadas nas duas coleções, em consequência dos processos de didatização desse material. Ao que parece, a principal causa dessas adaptações era a preocupação com as informações que precisariam, na visão dos autores, serem explicitadas.

É importante salientar, como já foi discutido, que ao inserir um gênero oriundo das esferas extraescolares à escola enquanto objeto de ensino, estamos realizando desde já um processo de didatização do texto. Foram identificados dois caminhos bem distintos nesse processo de didatização. O primeiro, mais comum, revelou que ao incluir esses gêneros, modificava-se a linguagem utilizada e faziam-se recortes. Muitas vezes, tais recortes dificultavam o reconhecimento das finalidades desses textos.

O segundo modo de efetuar a didatização, muito pouco presente, mantinha a linguagem original, com pistas para o reconhecimento da finalidade dos textos em seus suportes originais, bem como havia preocupação de, ao menos, situar o espaço de circulação original. Isto é, buscava-se manter fidelidade aos suportes originais e às características predominantes dos gêneros.

Nas coleções, a variedade textual, bem como a didatização dos gêneros para as idades destinadas parecem ter se apresentado como alvo de reflexão e prioridade. Outra semelhança foi quanto à frequência considerável de legendas e textos didáticos. Na coleção B, a esses seguiram-se - com uma porcentagem bem mais baixa - os mapas, as "apresentações", "objetivos dos capítulos" e as biografias. Entretanto, no que diz respeito à quantidade de textos, a coleção B disponibiliza cerca de menos 36\% de textos que a coleção A. Cabe observar, no entanto, que apesar de ter sido encontrada uma quantidade menor de textos, o total é ainda considerável, possibilitando um contato intenso com a linguagem escrita.

Apesar de haver variedade, foram encontrados alguns gêneros que ocupavam grande espaço na obra. Se observarmos a coleção A, os quatro primeiros gêneros apontados na Tabela 1 (as legendas, os textos didáticos, os glossários e os relatos históricos), chegaremos a um percentual de $76,8 \%$ do total presentes nos quatro volumes da coleção. Os últimos gêneros da mesma tabela (40 deles), apareceram de uma a cinco vezes apenas em todo o corpo da obra. Se dos $76,8 \%$ subtrairmos $1,74 \%$ dos relatos históricos que foram retirados de fontes oriundas de circulação extra-espaço escolar - mesmo que ainda de um outro espaço de ensino: 
o meio acadêmico - e 0,26\% da categoria denominada "textos didáticos" referentes às ocorrências com fontes indicadas, teremos um total de $74,8 \%$ de textos produzidos para inserção na coleção A. Isto é, textos que não foram selecionados de suportes de circulação extraescolar. Se ainda a esses somarmos as biografias/notas biográficas (1,41\% - 0,08\% $=1,33 \%$, considerando que, do total, uma ocorrência apresentou fonte e aspas identificando autoria de terceiros), as apresentações $(0,79 \%)$, as linhas do tempo $(0,61 \%)$ e notas informativas $(1,74 \%)$, teremos que $79,27 \%$ dos gêneros materializados no livro didático foram produzidos exclusivamente para fins de ensino. Não foram provenientes de outros espaços de circulação.

Após essas breves constatações, podemos mostrar evidências de que a coleção A possui forte preocupação na didatização dos conteúdos históricos a serem apresentados aos alunos dos primeiros ciclos do ensino fundamental, traduzida nos cerca de $80 \%$ de textos que poderíamos chamar de "adaptados" para fins da atividade de ensino-aprendizagem. Aos pouco mais de $20 \%$ restantes, esses sim provenientes de espaços de circulação extraescolares, restou a função no livro didático de servir de exemplos, de ilustrações e em poucos foram apresentados em "boxes" para problematização através de exercícios.

Dolz e Schneuwly (2004b) já advertiam que aqueles gêneros que entram na escola para tornarem-se objeto de ensino podem ser considerados variantes daqueles que serviram de referência. O contato com esses textos autênticos vem sendo apontado como muito importante para ajudar os alunos a interagir melhor com os textos fora da escola e a desenvolverem habilidades de leitura variadas para atender a diferentes propósitos interativos.

Todavia, não estamos afirmando que na escola é condenável o uso de textos cujas finalidades sejam exclusivamente escolares, ou seja, aprendizagem de conceitos e abordagens teóricas ou mesmo desenvolvimento de estratégias para lidar com a aprendizagem escolar, como, por exemplo, os resumos e fichamentos. Contudo, como salientamos anteriormente, há didatizações que asseguram as articulações com as práticas de linguagem extraescolares e há outras que imprimem ao texto características exclusivamente escolares. Isto é, há didatizações que garantem a manutenção das configurações e retomadas das funções extraescolares dos textos, a fim de propiciar reflexões sobre essas. Mas também, há didatizações que corrompem a apropriação de diferentes aspectos dos gêneros tais como esses se 
v. 7 (2)

490-516 ago/dez 2017

apresentam na sociedade. Isso por que há modificações em termos de conteúdo, linguagem e função exercida, tolhendo as possibilidades de análises desses. Muitas adaptações e fragmentações encontradas na obra são desse segundo tipo.

Assim, realizando o mesmo exercício de contabilizar os textos produzidos diretamente para a obra e as adaptações, na coleção B, poderemos somar as legendas, os textos didáticos, "objetivos" e "apresentações", textos produzidos especialmente para usufruto da obra, mais $27(3,75 \%)$ ocorrências dos demais gêneros que sofreram adaptações (mapas, reportagens, contos, lendas...) e chegarmos a um total de $87,05 \%$ do material textual.

Novamente, aqui cabe ressaltar que tais didatizações desses gêneros provocaram alterações substanciais nas características dos gêneros de origem. Entendemos esta adaptação sob a ótica de "simplificar a linguagem", ou mesmo na tentativa de "tornar o texto mais apreensível", "mais fácil" para os alunos. Desse modo, a linguagem literária, científica, jornalística modifica-se e passa a ser "didáticaliterária", "didática-científica", "didática-jornalística", algumas vezes com organização, forma composicional e estilo bem distantes daqueles tidos como originais.

\section{À guisa de conclusões}

A variedade de gêneros é uma preocupação explicitada nos documentos oficiais da área de ensino da língua portuguesa que também assumiu espaço importante na ficha de avaliação dos livros didáticos de História e igualmente nos Parâmetros Curriculares Nacionais da disciplina.

A partir da análise das coleções, inferimos que, num esforço perceptível, são inúmeras as tentativas de adequação a essa proposta. Uma variedade considerável de gêneros esteve presente em ambas as coleções. No entanto, a quantidade dos demais gêneros frente aos textos didáticos e àqueles referentes às propostas de atividades foram ínfimos.

Ainda ficaram marginalizados, seja por não atingirem percentagem favorável seja por não aparecerem na coleção, textos que contribuiriam para a discussão de diferentes temáticas fundamentais para o ensino da História, como as reportagens, leis, notícias e demais gêneros da esfera jurídica ou jornalística.

O recurso da adaptação e o uso de fragmentos de textos foram 
utilizados em ambas as coleções, o que levou-nos a inferir que o livro didático é tomado como um suporte que precisa apresentar uma linguagem fácil ao aluno, gerada por esses movimentos. A esse aspecto ressaltamos a necessidade de se considerar a perspectiva do letramento que diz respeito à possibilitar a aprendizagem dos diversos usos e funções que a linguagem pode assumir e que são tolhidos por essas iniciativas, prejudicando, inclusive, os usos referentes aos textos da ordem do argumentar ou aqueles com dimensões argumentativas.

Outro ponto fundamental foi a assunção da abordagem via eixos temáticos pelas coleções. Quanto mais distantes de uma perspectiva linear da história, as coleções apresentaram mais textos didáticos e menos relatos.

Com relação aos textos que apresentaram dimensões argumentativas, em ambas as coleções, ganharam destaque os textos didáticos, relatos históricos, reportagens e legendas. Aqueles que apresentaram menor frequência, nos quais acrescentam-se alguns da ordem do argumentar, foram tomados por textos ilustrativos ou complementares.

Consideramos indispensável, portanto, discutir mais profundamente sobre a importância da diversidade textual nos livros de História e sobre os papéis que desempenham para o ensino de capacidades fundamentais à construção dos conhecimentos nessa área do saber.

\section{Referências}

ANDRADE, R. M. L. de; LEAL, T. F.; BRANDÃO, A. C. P. Os gêneros textuais no livro didático: argumentação e ensino. In: CONGRESSO DE LEITURA DO BRASIL, 15., 2005, Campinas. Anais do $\mathbf{1 5}^{\mathbf{0}}$ COLE, Campinas, 2005. No prelo.

BAKHTIN, M. Estética da Criação Verbal. 4. ed., São Paulo: Martins Fontes, 2003.

BARDIN, L. Análise de Conteúdo. Lisboa: Edições 70, 1977.

BONINI, A. Gêneros textuais e cognição: um estudo sobre a organização cognitiva da identidade dos textos. Florianópolis: Insular, 2002.

BRASIL. Guia de Livros Didáticos de $\mathbf{1}^{\mathrm{a}}$ a $4^{\mathrm{a}}$ Séries - História. Programa Nacional do Livro Didático - MEC, 2006.

DIONíSIO, A. P. Gêneros Textuais e Multimodalidade. In: KARWOSKI, A. M.; GAYDECZKA, B.; BRITO, K. S. (Org.). Gêneros Textuais: reflexões e ensino. São Paulo: Parábola Editorial, 2011. p. 137-151. 
v. $7(2)$ $490-516$ ago/dez 2017
DOLZ, J.; SCHNEUWLY, B. Gêneros e progressão em expressão oral e escrita - elementos para reflexões sobre uma experiência suíça (francófona). In: SCHNEUWLY, B.; DOLZ, J. Gêneros Orais e Escritos na Escola. Campinas: Mercado de Letras, 2004a. p. 41-70.

DOLZ, J.; SCHNEUWLY, B. O oral como texto: como construir um objeto de ensino. In: SCHNEUWLY, B.; DOLZ, J. Gêneros Orais e Escritos na Escola. Campinas: Mercado de Letras, 2004b. p. 149-185.

ROSA, A.; BRESCÓ, I. Efeitos do conteúdo da forma na lembrança repetida das histórias nacionais. In: CARRETERO, M.; ROSA, A.; GONZÁLEZ, M. F. (Org.). Ensino da História e Memória Coletiva. Porto Alegre: Artmed, 2007. p. 167179.

SCHNEUWLY, B.; DOLZ, J. Gêneros Orais e Escritos na Escola. Campinas: Mercado de Letras, 2004.

SCHNEUWLY, B. Gêneros e tipos de discurso: considerações psicológicas e ontogenéticas. In: SCHNEUWLY, B.; DOLZ, J. Gêneros Orais e Escritos na Escola. Campinas: Mercado de Letras, 2004. p. 21-39.

SILVA, I. P. O. A escrita na escola: exercício escolar ou interação verbal? In: CONGRESSO DE LEITURA DO BRASIL, 12., 1999, Campinas. Anais do $\mathbf{1 2}^{\mathbf{0}}$ Congresso de Leitura do Brasil. Campinas: ALB, 1999.

SOARES, M. Letramento: um tema em três gêneros. 2. ed., 5. reimp. Belo Horizonte: Autêntica, 2002.

Recebido em: 9 de fev. de 2017.

Aceito em: 29 de jul. de 2017. 